\title{
Diazaisoindigo bithiophene and terthiophene copolymers for Application in Field-Effect Transistors and Solar Cells
}

\author{
Wan Yue, ${ }^{* a, b}$ Cheng Li, ${ }^{c}$ Xuelin Tian, ${ }^{a}$ Weiwei Li, ${ }^{* c}$ Marios Neophytou, ${ }^{d}$ Hu Chen, ${ }^{d}$ Weiyuan Du, ${ }^{d}$ Cameron \\ Jellatt, ${ }^{\mathrm{b}}$ Hung-Yang Chen, ${ }^{\mathrm{b}}$ Ada Onwubiko ${ }^{\mathrm{b}}$ and Iain McCulloch ${ }^{\mathrm{b}, \mathrm{d}}$ \\ ${ }^{a}$ Key Laboratory for Polymeric Composite and Functional Materials of Ministry of Education, School of Material \\ and Material Engineering, Sun Yat-Sen University, Guangzhou 510275, China. \\ Emai1: yuew5@mail.sysu. edu.cn \\ ${ }^{b}$ Department of Chemistry and Centre for Plastic Electronics, Imperial College London, SW7 2AZ, United Kingdom. \\ ${ }^{\circ}$ Beijing National Laboratory for Molecular Sciences, CAS Key Laboratory of Organic Solids, Institute of \\ Chemistry, Chinese Academy of Sciences, Beijing 10090, China. \\ Email: 1iweiwei@iccas. ac.cn \\ ${ }^{d}$ King Abdullah University of Science and Technology (KAUST), KSC, Thuwal. 23955-6900, Saudi Arabia.
}

\begin{abstract}
Two donor-acceptor conjugated polymers with azaisoindigo as acceptor units and bithiophene and terthiophene as donor units have been synthesized by Stille polymerization. These two polymers have been successfully applied in field-effect transistors and polymer solar cells. By changing the donor component of the conjugated polymer backbone from bithiophene to terthiophene, the density of thiophene in the backbone is increased, manifesting as a decrease in both ionization potential and in electron affinity. Therefore, the charge transport in field-effect transistors switches from ambipolar to predominantly hole transport behavior. PAIIDTT exhibits hole mobility up to $0.40 \mathrm{~cm}^{2} /$ s and electron mobility of $0.02 \mathrm{~cm}^{2} / \mathrm{Vs}$, whereas PAIIDTTT exhibits unipolar hole mobility of $0.62 \mathrm{~cm}^{2} / V s$. Polymer solar cells were fabricated based on these two polymers as donors with $\mathrm{PC}_{60} \mathrm{BM}$ and $\mathrm{PC}_{70} \mathrm{BM}$ as acceptor where PAIIDTT shows a modest efficiency of $2.6 \%$ with a very low energy loss of $0.55 \mathrm{eV}$, while PAIIDTTT shows a higher efficiency of $6.2 \%$ with a higher energy loss of $0.74 \mathrm{eV}$. Our results suggest that azaisoindgo is a useful building block for the development of efficient polymer solar cells with further improvement possibility by tuning the alternative units on the polymer backbone.
\end{abstract}

Semiconducting polymers for organic field-effect transistors (OFETs) and organic solar cells (OSCs) have attracted significant interest in recent years due to their low cost, light weight and their ability for large area solution processing compatible with flexible substrates. ${ }^{1,2}$ Innovative polymer design has led to very high charge carrier mobility in OFETs and power conversion efficiencies (PCEs) in OSCs. ${ }^{3,4,5,6}$ Molecular design strategies are continuing to be devised to explore new materials to increase performance. ${ }^{7}$ Side-chain length optimization and core modification have been considered as effective 
approaches for designing semiconductors with tunable intramolecular and intermolecular interactions. ${ }^{8,}$ $9,10,11,12$

Isoindigo (IID) is a well-studied acceptor unit consisting of an electron-deficient symmetrical lactam core fused with a phenyl group, featuring strong electron-deficient and coplanarity properties. IID based conjugated polymers comprising an IID core and co-monomer alternating repeat units, have been intensively investigated for their application in OFETs and PSCs, since 2010. ${ }^{13,14}$ IID copolymers show high charge carrier mobility due in part to the strong intermolecular interactions associated with the offaxis dipole moment of the IID. Additionally, donor-acceptor conjugated copolymers based on IID core can be designed to exhibit low band gaps, and therefore can efficiently harvest photons from solar irradiation. In the early period of IID research, phenyl rings were selected due primarily to more straightforward synthesis. However, this phenyl group promotes a relatively large dihedral angle between the phenyl unit and copolymerized, which is not optimal for achieving effective intramolecular polymer conjugation and charge transport as well as somewhat suppressing the intermolecular interactions. ${ }^{15}$ IID core modification has been subsequently explored through changing the choice of aromatic flanking groups with both energy level and polymer conformation tuning accordingly. ${ }^{16,17,18}$ Alternative aromatic groups to phenyl have been recently reported, including both thiophene flanked isoindigo, ${ }^{16}$ thieno[3,2- b] thiophene flanked isoindigo ${ }^{17}$ and thieno[3,2-b][1]benzothiophene isoindigo. ${ }^{18}$ The dihedral angle can be reduced and give a more planar backbone by using flankingthiophene rings. These building blocks were incorporated into polymers in order to tune the polymer conformation, energy levels, absorption spectra and crystalline properties and therefore achieve efficient charge transport. Very recently we also reported the synthesis and promising charge transport behavior of an acceptor-acceptor (A-A) and a donor-acceptor (D-A) polymers containing an azaisoindigo (AIID) unit. ${ }^{19}$ In this case, the steric effect could be alleviated from the neighbouring co-repeat units due to the 7nitrogen atoms and the electron-deficient character of pyridine rings, the A-A polymer exhibits unipolar electron mobility as high as $1.0 \mathrm{~cm}^{2} / \mathrm{Vs}$, and D-A type polymer exhibits ambipolar charge transport behavior with electron mobility up to $0.5 \mathrm{~cm}^{2} / \mathrm{Vs}$ and hole mobility to $0.2 \mathrm{~cm}^{2} / \mathrm{Vs}$. The charge carrier mobility of PAIIDTT copolymers with side chain of 2-decyltetradecyl has also been reported to show good hole mobility. ${ }^{20}$ These results have encouraged us to further explore AIID based copolymers, and extend this investigation to solar cell applications. Herein, two AIID copolymers with alternating bithiophene and terthiophene as comonomers have been designed and synthesized for application in organic electronic devices. 

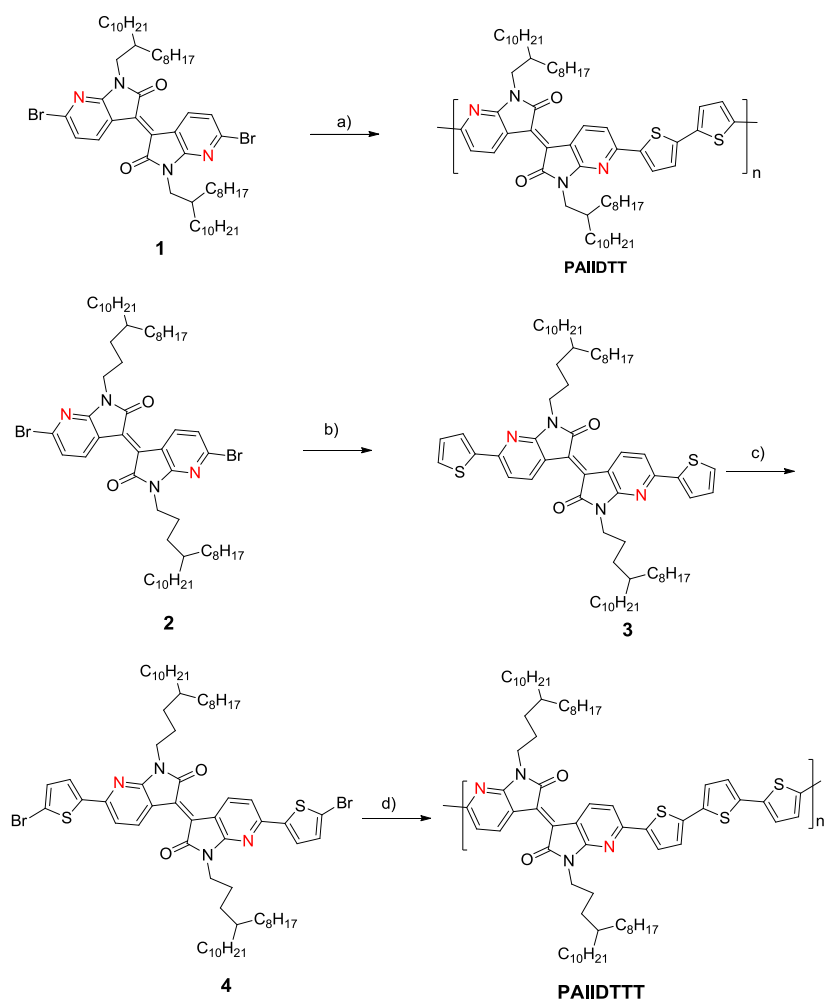

Scheme 1: Synthetic routes to PAIIDTT and PAIIDTTT: a) 5,5'-Bis(trimethylstannyl)-2,2'-bithiophene, $\mathrm{Pd}_{2}(\mathrm{dba})_{3}, \mathrm{P}(\mathrm{o} \text {-tol })_{3}$, chlorobenzene, microwave, $85 \%$; b) 2-tributylstannylthiophene, $\mathrm{Pd}_{2}(\mathrm{dba})_{3}, \mathrm{P}(o \text {-tol })_{3}$, toluene, reflux, $84 \%$; c) NBS, $\mathrm{CHCl}_{3}, 63 \%$; d) 2,5-bis(trimethylstannyl)thiophene, $\mathrm{Pd}_{2}(\mathrm{dba})_{3}, \mathrm{P}(o-\mathrm{Tol})_{3}$, chlorobenzene, microwave, $92 \%$.

\section{Synthesis and Characterization}

The synthetic routes for the PAIIDTT and PAIIDTTT are shown in Scheme 1. The monomer 1 with 2octyldodecyl side chain was prepared according to our previous paper. ${ }^{19}$ Compound $\mathbf{2}$ was achieved via similar procedures while using 4-octyldodecyl alkyl chain with different branch point (Scheme 1). It is known that the branch point of the alkyl chain has a strong influence on the $\pi$ - $\pi$ stacking. Compound 3 was prepared by Stille coupling between $\mathbf{2}$ and 2-tributylstannylthiophene in a good yield, followed by bromination to yield the monomer 4 . By employing polymerization with $\mathrm{Pd}_{2}(\mathrm{dba})_{3} / \mathrm{P}(o \text {-tol })_{3}$ catalyst under microwave irradiation, PAIIDTT can be obtained from monomer 1 and 2,5bis(trimethylstannyl)thienothiophene. Similar polymers with longer length of 2-decyltetradecyl side chains have been reported for thin film transistor application. ${ }^{20}$ The PAIIDTTT was prepared by the same Stille polymerization condition between monomer 4 and bis(trimethylstannyl)thiophene. Both of the AlID polymers show good solubility in chlorobenzene (CB) and o-dichlorobenzene (o-DCB). Gel 
permeation chromatography (GPC) with $\mathrm{CB}$ as eluent at $80{ }^{\circ} \mathrm{C}$ was used to determine the molecular weight of the polymers (Figure S1 and Figure S2). Both of the polymers exhibit very high average molecular weight $\left(M_{\mathrm{n}}\right)$. The PAIIDTT shows a $M_{\mathrm{n}}$ of $188.7 \mathrm{~kg} \mathrm{~mol}^{-1}$ with a polydispersity index (PDI) of 3.36, and the PAIIDTTT has a $M_{\mathrm{n}}$ of $202.8 \mathrm{~kg} \mathrm{~mol}^{-1}$ with a PDI of 2.07. Thermogravimetric analysis demonstrated excellent thermal stability of these polymers, which had a decomposition temperature of $410{ }^{\circ} \mathrm{C}$ and $415^{\circ} \mathrm{C}$ respectively (5\% weight loss).
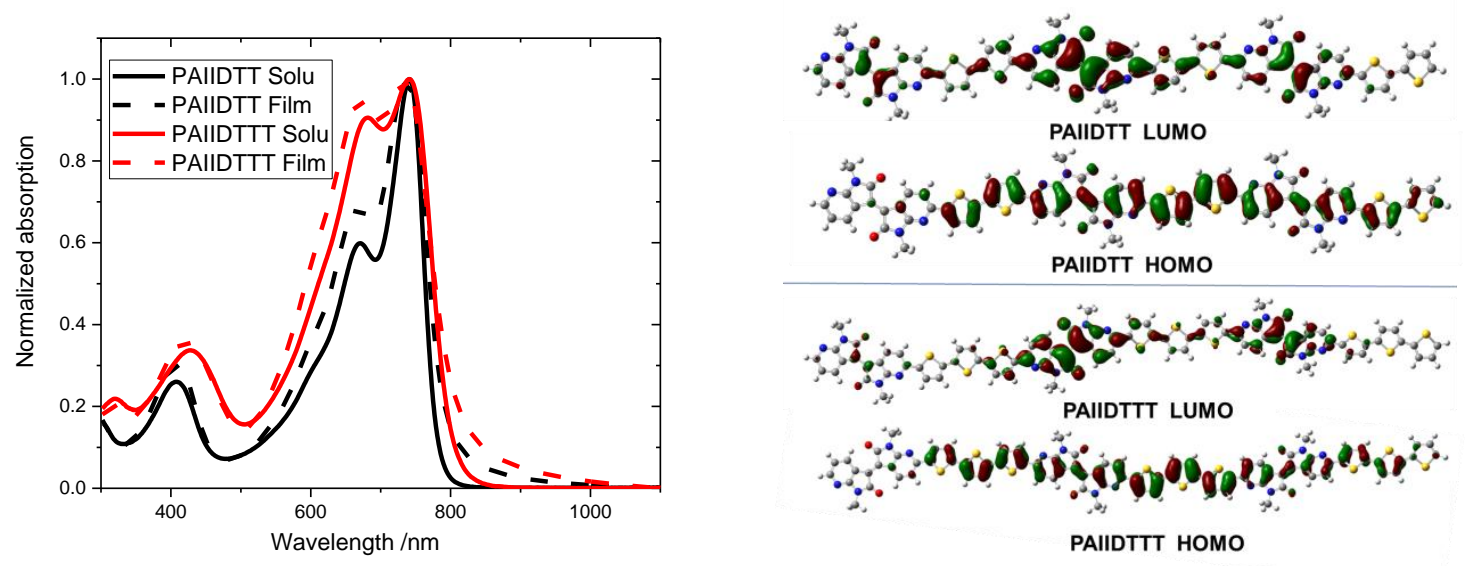

Figure 1: (a) Normalized UV-vis-NIR absorption spectra of PAIIDTT and PAIIDTTT in dilute chlorobenzene solution and as-cast thin films form chlorobenzene solution on quartz; (b) Calculated molecular orbitals of the trimers of PAIIDTT and PAIIDTTT ( $\omega$ B97X/6-31+G(d) ).

\section{Optical Properties}

The UV-vis NIR absorption spectra of PAIIDTT and PAIIDTTT in CB solution and as cast films are shown in Figure 1a. Both polymers show two distinct features both in solution and in the solid state. The strong low energy band from $600-800 \mathrm{~nm}$ can be attributed to the intramolecular charge transfer between the electron deficient azaisodingo unit and the electron donating bithiophene and terthiophene, confirming the strong electron-withdrawing effect of the azaisoingido core. According to the DFT ( $\omega$ B97X/6$31+G(d)$ ) calculation results, the HOMO distributions are well delocalized along the polymer chains, in contrast, the LUMO distributions are mostly localized on the azaisoindigo core (Figure 1b). The dihedral angle between the azaisoingo and the neighboring thiophene repeat unit is almost planar. The absorption spectrum of PAIIDTT in solution shows a maximum peak at $741 \mathrm{~nm}$, and slightly broader absorption spectrum without significant change of the maximum peak $\left(\lambda_{\max }=736 \mathrm{~nm}\right)$ in the solid state, indicating some degree of $\pi-\pi$ stacking occurs in the thin films, which is beneficial for improving the 
charge transport of the resulting films. In comparison with PAIIDTT, PAIIDTTT shows slightly red shifted and broader absorption spectra both in solution profile and in the solid state also due to the additional thiophene ring. Similarly with PAIIDTT, the absorption profile of the thin film of PAIIDTTT is slightly broader than that of the solution profile. The onset of the absorption in the solid state is $795 \mathrm{~nm}$ and $816 \mathrm{~nm}$, which corresponds to an optical band gap of approximately 1.6 and $1.5 \mathrm{eV}$ for PAIIDTT and PAIIDTT respectively, which are optimalfor PSCs. ${ }^{21}$ The ionization potentials (IP) of the polymers as thin films spin cast from chlorobenzene solution were measured, using photoelectron spectroscopy in air (PESA), to be $5.36 \mathrm{eV}$ for PAIIDTT and $5.21 \mathrm{eV}$ for PAIIDTTT. The electron affinity (EA) estimated from the optical band gap to corresponding IPs were found $3.80 \mathrm{eV}$ for PAIITT and $3.69 \mathrm{eV}$ for PAIIDTTT (Table 1). The higher IP and EA for PAIIDTTT than that of PAIIDTT can be ascribed to the stronger electron donating character of the TTT unit than that of TT unit.

Table 1. Molecular Weights and Optical Properties and Frontier Molecular Orbital Energy Levels of the Polymers.

\begin{tabular}{lcccccccc}
\hline Polymer & $M_{\mathrm{n}}[\mathrm{KDa}]^{\mathrm{a}}$ & $\begin{array}{c}M_{\mathrm{w}} \\
{[\mathrm{KDa}]^{\mathrm{a}}}\end{array}$ & $\mathrm{PDI}^{\mathrm{a}}$ & $\begin{array}{l}\lambda_{\max }(\text { solu }) \\
{[\mathrm{nm}]}\end{array}$ & $\begin{array}{l}\lambda_{\max }(\text { film }) \\
{[\mathrm{nm}]}\end{array}$ & $\begin{array}{l}\mathrm{IP}^{\mathrm{b}} \\
{[\mathrm{eV}]}\end{array}$ & $\begin{array}{l}\mathrm{EA}^{\mathrm{c}} \\
{[\mathrm{eV}]}\end{array}$ & $\begin{array}{l}E_{\mathrm{g}}{ }^{\mathrm{g}} \\
{[\mathrm{eV}]}\end{array}$ \\
\hline PAIIDTT & 188.7 & 633.2 & 3.4 & 741 & 736 & 5.36 & 3.80 & 1.56 \\
PAIIDTTT & 202.8 & 420.1 & 2.1 & 741 & 735 & 5.21 & 3.69 & 1.52 \\
\hline
\end{tabular}

${ }^{a}$ Number-average and weight-average molecular weights $\left(M_{\mathrm{n}}, M_{\mathrm{w}}\right)$ and polydispersity indexes $\left(\mathrm{PDI}=M_{\mathrm{w}} /\right.$ $M_{n}$ ) determined by gel-permeation chromatography using polystyrene standards and chlorobenzene $\left(80^{\circ} \mathrm{C}\right)$ as eluent. ${ }^{b}$ Thin film spin-cast on glass substrates from chlorobenzene solution. IP measured by photoelectron spectroscopy in air (PESA). ${ }^{d}$ EA estimated by equation EA $=I P-E_{\mathrm{g}}{ }^{\text {optical }}$. ${ }^{e}$ Estimated by the onset of the thin film absorption spectra $\left(E_{\mathrm{g}}=1240 / \lambda_{\text {onset }}\right)$.

Table 2: Bottom gate/bottom contact OFET device characteristics for the polymers PAIIDTT and PAIIDTTT.

\begin{tabular}{lllllr}
\hline Polymer & $T_{\text {anneal }}\left[{ }^{0} \mathrm{C}\right]$ & $\begin{array}{c}\mu_{\mathrm{e} 1}\left(\mu_{\mathrm{e} 2}\right) \\
{\left[\mathrm{cm}^{2} / \mathrm{Vs}\right]}\end{array}$ & $\begin{array}{l}\mu_{\mathrm{h} 1}\left(\mu_{\mathrm{h} 2}\right) \\
{\left[\mathrm{cm}_{2} / \mathrm{Vs}\right]}\end{array}$ & $I_{\text {on }} / I_{\text {off }}$ & $V_{\text {th }}[\mathrm{eV}]$ \\
\hline PAllDTT & 150 & 0.02 & 0.34 & $1 \times 10^{5}$ & 52.6 \\
PAIIDTT & 250 & - & $0.40(0.09)$ & $7 \times 10^{6}$ & -22.4 \\
PAIIDTTT & 250 & - & $0.62(0.034)$ & $1 \times 10^{6}$ & -14.4 \\
\hline
\end{tabular}



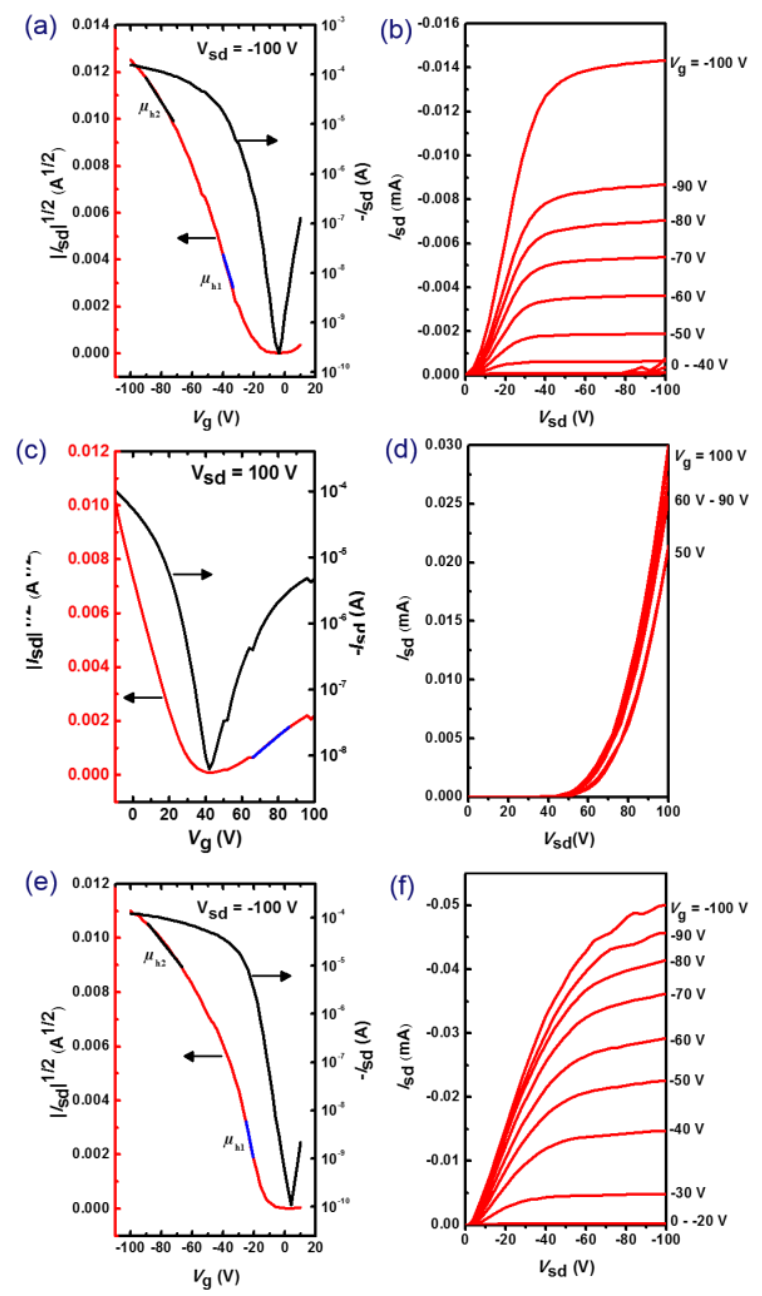

Figure 2: Transfer and output characteristics of PAIIDTT annealed at $250{ }^{\circ} \mathrm{C}(\mathrm{a}, \mathrm{b})$ and $150{ }^{\circ} \mathrm{C}(\mathrm{c}, \mathrm{d})$ and PAIIDTTT annealed at $250{ }^{\circ} \mathrm{C}(\mathrm{e}, \mathrm{f})$.

To study the semiconducting properties of the polymers, thin film OFET devices with a bottom gatebottom contact (BGBC) configuration based on the PAIIDTT and PAIIDTTT were fabricated to evaluate the charge transport characteristics of the azaisoindigo polymers. Both polymer films were thermally annealed. The mobility was calculated from the saturation regime. The semiconducting layers were deposited onto octadecyltrichlorosilane (OTS) modified $\mathrm{SiO}_{2} / \mathrm{Si}$ substrate. Polymer layers were spincasted from chloroform and $10 \%$ o-DCB solutions with concentrations of $7 \mathrm{mg} / \mathrm{ml}$ for PAIIDTT and PAIIDTTT. The performance of both as-cast and thermally annealed films are shown in the Table 2 and Table S1. PAIIDTT exhibits hole-dominated ambipolar transport characteristics. PAIIDTT shows hole 
mobility of $0.15 \mathrm{~cm}^{2} / \mathrm{Vs}$ based on as cast film, with slightly improvement observed at high temperature annealing . Figure 2a-d show the typical transfer and output characteristics recorded at $V_{D}=-100 \mathrm{~V}$ and $V_{D}=100 \mathrm{~V}$ for PAIIDTT annealed for 10 mins at $250{ }^{\circ} \mathrm{C}$ and $150{ }^{\circ} \mathrm{C}$, corresponding to the highest hole transport mobility of $0.4 \mathrm{~cm}^{2} / \mathrm{Vs}$ and electron transport mobility of $0.02 \mathrm{~cm}^{2} / \mathrm{Vs}$. With an additional thiophene ring per donor repeat unit on the polymer backbone, PAIIDTTT displays hole only transport characteristics. For the device based on as cast films, hole mobility of up to $0.23 \mathrm{~cm}^{2} / \mathrm{Vs}$ was obtained, with thermally annealed device mobility ranging from $0.50 \mathrm{~cm}^{2} / \mathrm{Vs}$ at $150{ }^{\circ} \mathrm{C}, 0.37 \mathrm{~cm}^{2} / \mathrm{Vs}$ at $200{ }^{\circ} \mathrm{C}$ and $0.62 \mathrm{~cm}^{2} / \mathrm{Vs}$ at $250^{\circ} \mathrm{C}$.

(a)

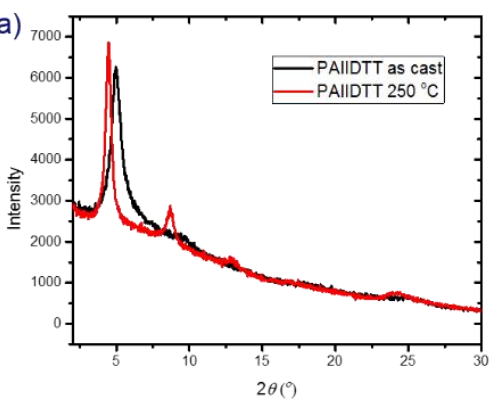

(c)

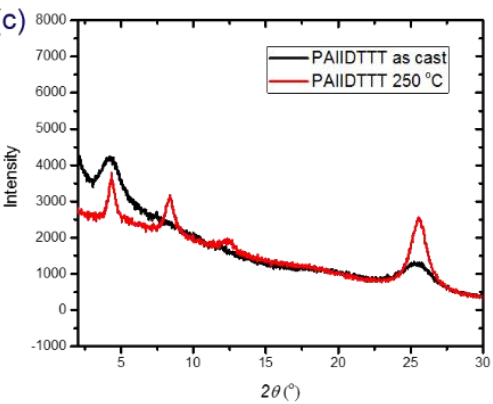

(b)

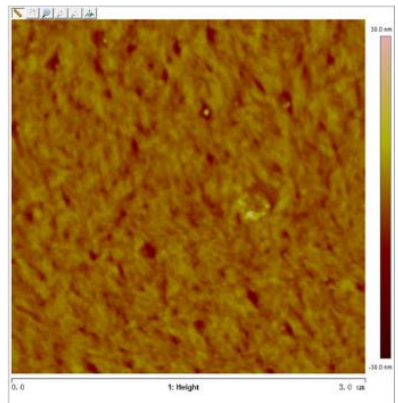

(d)

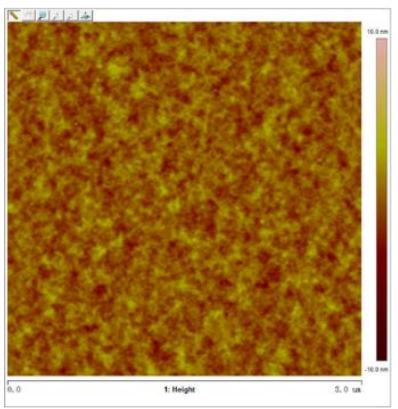

Figure 3: One dimensional specular XRD data obtained from drop-cast thin films $(7 \mathrm{mg} / \mathrm{mL}$ chloroform and $10 \% o$-DCB solutions) on Si wafer as cast and $250{ }^{\circ} \mathrm{C}$ of PAIIDTT (a) and PAIIDTTT (c). AFM height images of thermal annealed films at $250^{\circ} \mathrm{C}$ of PAIIDTT (b) and PAIIDTTT (d). (Thermal annealing of the films were conducted at $250^{\circ} \mathrm{C}$ for $10 \mathrm{~min}$.) The RMS is $2.6 \mathrm{~nm}$ and $1.1 \mathrm{~nm}$ for $\mathrm{b}$ and $\mathrm{d}$ respectively.

The morphology of polymer films were characterized by out of plane X-ray diffraction (XRD) and atomic force microscopy (AFM). XRD diffraction measurements revealed both of the polymers have high degree of crystallinity. As shown in Figure 3a with a relatively broad reflection peak at $2 \theta=4.96^{\circ}$ was observed for the pristine film of PAIDTT, corresponding to the (100) diffraction peak with an interlayer spacing of $17.8 \AA$. After thermal annealing at $250{ }^{\circ} \mathrm{C},(100)$ diffraction peak $\left(2 \theta=4.47^{\circ}\right)$ became sharper 
and slightly more intense along with the presence of a $(200)$ peak $\left(2 \theta=8.69^{\circ}\right)$ and $(300)$ peak $(2 \theta=$ $12.87^{\circ}$ ), corresponding to a lamellar d-spacing of $19.75 \AA$. Interestingly, PAIIDTTT adopts a different molecular orientation than PAIIDTTT, as shown in Fig 3c. Apart from a weak (100) diffraction peak at $2 \theta$ $=4.22$, a very strong $(010)$ diffraction peak at $2 \theta=25.42$, corresponding to a stacking distance of $3.50 \AA$ was also observed for as cast film of PAIIDTTT. Upon annealing at $250{ }^{\circ} \mathrm{C}$, both of the (100) and (010) diffraction peaks became narrower and more intense corresponding to a lamellar d-spacing of $20.44 \AA$ and a pi-pi stacking distance of $3.52 \AA$, along with the presence of observable (200) and (300) diffraction peaks. These XRD results indicate that the PAIIDTT backbone adopts an edge-on packing orientation in the solid state, while PAIIDTTT adopts mixed orientation with edge-on and face-on packing. Thermal annealing could noticeably improve the order of the polymers, leading to ordered, crystalline structures in the solid state.

AFM images of the two polymers across the range of annealing temperatures are shown in Figure S5 and Figure 3. For polymer PAIIDTT, it is clear to see that there is no obvious change in surface morphology and roughness for thin films at annealing temperature at 150 and $200{ }^{\circ} \mathrm{C}$. A pronounced change at annealed temperature of $250{ }^{\circ} \mathrm{C}$ can be observed for the films of PAIIDTT with a smoother and more defined morphology. PAIIDTT also shows a very similar surface and roughness, going from as cast polymer film to $200{ }^{\circ} \mathrm{C}$, while the polymer films becoming slight coarser and the domain size became larger at $250{ }^{\circ} \mathrm{C}$. Both of the changed morphology at $250{ }^{\circ} \mathrm{C}$ is consistent with the changed packing behaviors observed from XRD and slightly enhanced OFET mobility.

\section{Polymer solar cells}

Polymer solar cells based on the polymers as light absorbing electron donor and a fullerene derivative phenyl- $\mathrm{C}_{71}$-butyric acid and methyl ester $\left(\mathrm{PC} \mathrm{C}_{71} \mathrm{BM}\right)$ or phenyl- $\mathrm{C}_{61}$-butyric acid and methyl ester $\left(\mathrm{PC}_{61} \mathrm{BM}\right)$ as electron acceptor were prepared with an inverted configuration with $\mathrm{ITO} / \mathrm{ZnO}$ and $\mathrm{MoO}_{3} / \mathrm{Ag}$ as electron and hole transport layers. The active layers were spin coated from a chloroform and chlorobenzene blend solution with the ratio of the donor to the acceptor is $1: 2$, in which the additive (2.5 wt\% 1,8-diiodooctane (DIO)) was added to optimize the performance, as summarized in Table 2. When photoactive layers based on PAIIDTT:PC ${ }_{71} B M$ were spin coated from an additive containing chloroform solution (2.5\% DIO), the solar cells exhibited a PCE of $2.57 \%$ with a short-circuit current density $\left(J_{\text {sc }}\right)$ of $5.16 \mathrm{~mA} \mathrm{~cm}^{-2}$, open-circuit voltage $\left(V_{\text {oc }}\right)$ of $1.01 \mathrm{~V}$ and fill factor (FF) of 0.49 (Figure 3a). PAIIDTT and $\mathrm{PC}_{71} \mathrm{BM}$ processed with chloroform (CF): $10 \% 0$-DCB and 0 -DCB: $2.5 \%$ DIO, exhibited the same PCE of $1.84 \%$. A PCE of $2.08 \%$ was achieved when PAIIDTT and PC ${ }_{61} \mathrm{BM}$ were spin coated from o- 
DCB solution with 2.5\% DIO. Although PAIIDTT devices exhibited relative low power conversion efficiency $(P C E)$, the $E_{\text {loss }}$ is very low $\left(E g-V_{o c}=0.55 \mathrm{eV}\right)$ with a the high $V_{o c}$ of $1.01 \mathrm{eV}$. The large $V_{o c}$ of the solar cells can be attributed to the high IP of PAIIDTT, since the $V_{\text {oc }}$ is associated with the energy level difference between the IP of the donor and the EA of the acceptor. ${ }^{22}$

Compared with PAIIDTT, PAIIDTTT exhibited a slightly higher PCE of $3.26 \%$ when the polymer and $\mathrm{PC}_{71} \mathrm{BM}$ was proceed in a CF solution with $2.5 \% \mathrm{DIO}$, with a higher $J_{s c}$ of $11.02 \mathrm{~mA} \mathrm{~cm}^{-2}$, lower $V_{\text {oc }}$ of 0.76 $\mathrm{eV}$ and FF of 0.39. Similar PCEs around $4.4 \%$ were obtained when PAIIDTTT and PC ${ }_{71}$ BM was fabricated with CF: $10 \%$ o-DCB or o-DCB: $2.5 \% \mathrm{DIO}$. When $\mathrm{PC}_{61} \mathrm{BM}$ was used as acceptor, PAIIDTTT exhibited a relative high PCE of $6.16 \%$ with $J_{\mathrm{sc}}$ of $13.10 \mathrm{~mA} \mathrm{~cm}{ }^{2}, V_{\mathrm{oc}}$ of $0.78 \mathrm{eV}$ and a FF of 0.60 . Both PAIIDTT and PAIIDTT when blended with $\mathrm{PC}_{61} \mathrm{BM}$ exhibited higher FF values when compared to $\mathrm{PC}_{71} \mathrm{BM}$-based mixtures. This might originate from phase separation differences. Much lower $V_{\text {oc }}$ of PAIIDTTT (around $0.78 \mathrm{eV}$ ) than that of PAIIDTT has been attributed to its lower IP.

Table 2. OPV device performance characteristics of polymers PAIIDTT and PAIIDTTT with PC 71 $_{1} B$ and $\mathrm{PC}_{61} \mathrm{BM}$ fullerene acceptors (polymer: fullerene $1: 2 \mathrm{w} / \mathrm{w}$ blend ratio) using an inverted device architecture.

\begin{tabular}{|c|c|c|c|c|c|c|}
\hline Polymer: PCBM & Solvent & Thickness[nm] & $J_{s c}\left(\mathrm{~mA} / \mathrm{cm}^{2}\right)$ & $V_{\text {oc }}(\mathrm{V})$ & $\mathrm{FF}$ & PCE(\%) \\
\hline PAIIDTT:PC ${ }_{71} B M$ & CF:2.5\%DIO & 72 & 5.16 & 1.01 & 49.2 & 2.57 \\
\hline PAIIDTT:PC ${ }_{61} B M$ & $o$-DCB:2.5\%DIO & 99 & 3.25 & 1.01 & 63.0 & 2.08 \\
\hline PAIIDTTT:PC ${ }_{71} \mathrm{BM}$ & $\mathrm{CF}: 2.5 \% \mathrm{DIO}$ & 76 & 11.02 & 0.76 & 39.1 & 3.26 \\
\hline PAIIDTTT:PC ${ }_{61} B M$ & $o-\mathrm{DCB}: 2.5 \% \mathrm{DIO}$ & 75 & 13.10 & 0.78 & 60.3 & 6.16 \\
\hline
\end{tabular}



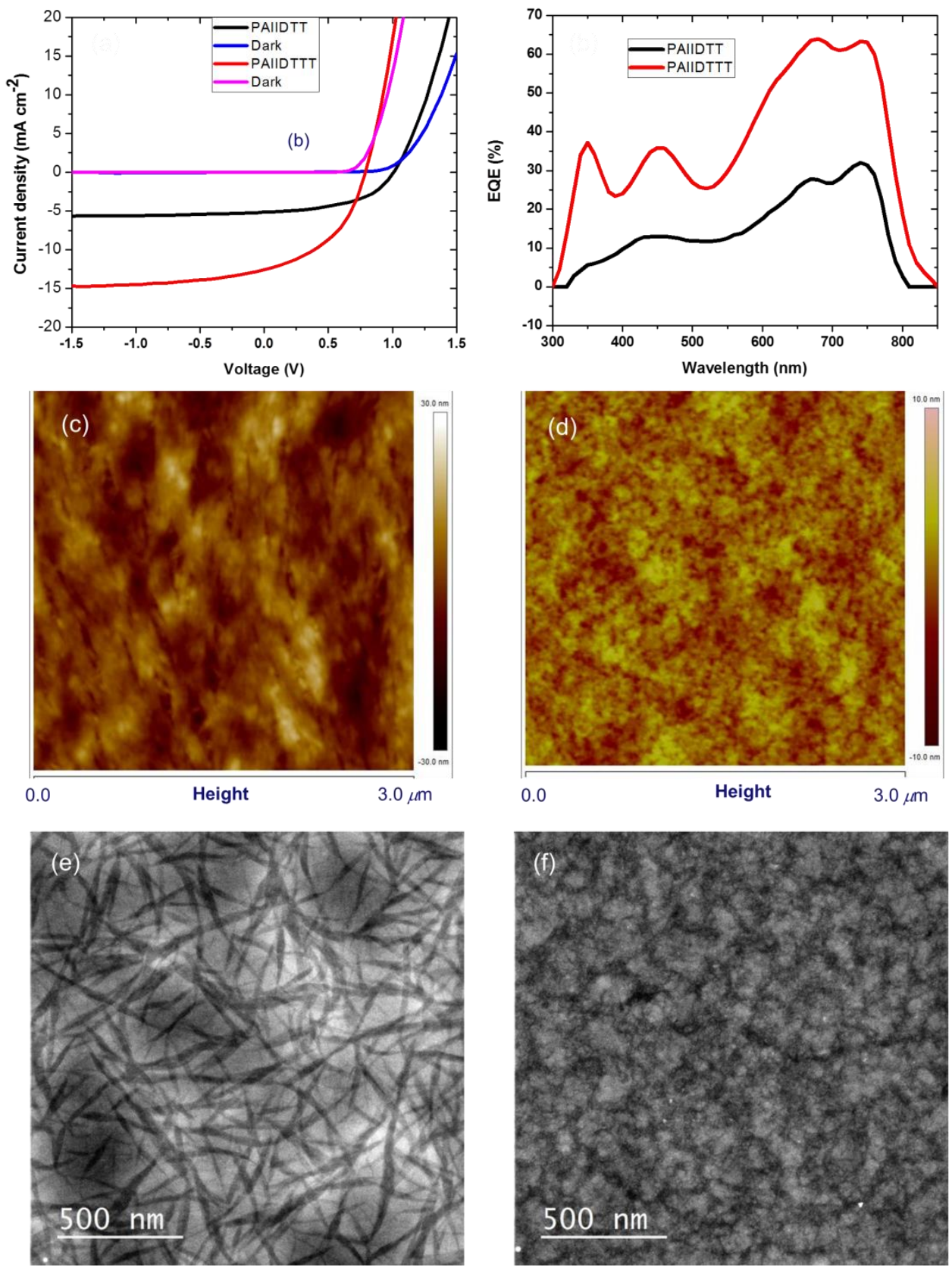

Figure 4: (a) J-V plots in the dark and under white light illumination of the PAIIDTT: $P C_{71} B M$ and PAIIDTTT: PC ${ }_{61} \mathrm{BM}$; (b) EQE of the optimized PAIIDTT: PC $\mathrm{C}_{71} \mathrm{BM}$ and PAIIDTTT: $\mathrm{PC}_{61} \mathrm{BM}$ solar cells; AFM height images and DF-TEM of the PAIIDTT: PC ${ }_{71} B M ;(c, e)$ and PAIIDTTT: PC 61 BM; $(d, f)$. RMS roughness is $5.3 \mathrm{~nm}$ and $1.5 \mathrm{~nm}$ for $\mathrm{c}$ and $\mathrm{d}$ respectively. 
The high external quantum efficiency (EQE) curves with the best devices of PAIIDTT and PAIIDTTT are shown in Figure 4b. A broad spectral response in the $400-800 \mathrm{~nm}$ region was observed for both devices, with the maximum observed around $750 \mathrm{~nm}$ for PAIIDTT and $780 \mathrm{~nm}$ for PAIIDTTT, while much lower response from 300 to $550 \mathrm{~nm}$, is predominantly due to the low absorption extinction coefficient of both $\mathrm{PC}_{61} \mathrm{BM}$ and polymers in this wavelength region. The high $J_{s c}$ of PAIIDTTT is also consistent with EQE with the maximum EQE above 65\%, while PAIIDTT based cells have a relatively low EQE with a maximum EQE of $32 \%$. The microstructure of the blend films were studied by Atomic Force Microscope (AFM) and dark-field Transmission Electron Microscopy (DF-TEM). In the AFM height images of active layers (Figure $4 \mathrm{c}$ and $4 \mathrm{~d}$ ), both films exhibit relatively low roughness with $5.3 \mathrm{~nm}$ and $1.5 \mathrm{~nm}$ for PAIIDTT and PAIIDTTT blends respectively. Unfavorable morphology is observed for PAIIDTT:acceptor blends which is reflected to low photovoltaic device performance, a statement also supported by DF-TEM (Figure 4e) Concerning PAIIDTT:acceptor systems, DF-TEM images (Figure $4 \mathrm{f}$ and Figure $\mathrm{S6}$ ) suggest that in the case of $\mathrm{PC}_{61} \mathrm{BM}$, both components are forming relatively small domains where in the $\mathrm{PC}_{71} \mathrm{BM}$ case extensive aggregation may be taking place.

\section{Conclusions}

Two Azaisoindigo conjugated polymers flanked with bithiophene and terthiophene were explored for application in organic electronics devices. The bithiophene polymer shows ambipolar behavior with hole mobility of $0.40 \mathrm{~cm}^{2} / \mathrm{Vs}$ and electron mobility of $0.02 \mathrm{~cm}^{2} / \mathrm{Vs}$ in FETs, and the terthiophene copolymer exhibits unipolar hole mobility of $0.62 \mathrm{~cm}^{2} / V s$. Investigation of photovoltaic devices based on these two polymers show quite different PCEs in solar cells. The bithiophene polymer shows a relative low efficiency of $2.6 \%$ while with a $\mathrm{V}_{\text {oc }}$ up to $1.01 \mathrm{~V}$ and a very low energy loss of $0.55 \mathrm{eV}$, terthiophene polymer shows a high efficiency of $6.14 \%$. These results show that the polarity of the charge transport properties and the photovoltaic performance of the conjugated polymers can be effectively tuned via changing the thiophene density along the backbones.

\section{Acknowledgements}

This work was supported by Marie Curie Intra-European Fellowship with the 7th European Community Framework Programme (FP7-PEOPLE-2013-IEF-622187). The authors thank EC FP7 Project SC2, EC FP7 Project ArtESun, EC FP7 Project PolyMed, and EPSRC Project EP/G037515/1 for financial support.

\section{Notes and references}

[1]. A. C. Arias, J. D. Mackenzie, I. McCulloch, J. Rivnay and A. Salleo, Chem. Rev.; 2010, 110, 3. 
[2]. Dou, L. Liu, Y. Hong, Z. Li, G and Yang, Y. Chem. Rev.; 2015, 115, 12633.

[3]. D. Venkateshvaran, M. Nikolka, A. Sadhanala, V. Lemaur, M. Zelazny, M. Kepa, M. Hurhangee, A. J.Kronemeijer, V. Pecunia, I. Nasrallah, I. Romanov, K. Broch, I. McCulloch, D. Emin, Y. Olivier, J. Cornil, D. Beljonne and H. Sirringhaus, Nature 2014, $515,384$.

[4]. M. Saito, I. Osaka, Y. Suda, H. Yoshida and K. Takimiya, Adv. Mater.; 2016, 28, 6921.

[5]. G. Kim, S. J. Kang, G. K. Dutta, Y. K. Han, T. J. Shin, Y. Y. Noh and C. Yang, J. Am. Chem. Soc.; 2014, $136,9477$.

[6]. J. Cao, L. Qian, F. Lu, J. Zhang, Y. Feng, X. Qiu, H-L Yip and L. Ding, Chem. Commun.; 2015, 51, 11830.

[7]. P. M. Beaujuge and J. M. J. Fréchet, J. Am. Chem. Soc.; 2011, 133, 20009.

[8]. B. N. Christian, M. Turbiez and I. McCulloch, Adv. Mater.; 2013, 25, 1859.

[9]. I. McCulloch, R. S. Ashraf, L. Biniek, H. Bronstein, C. Combe, J. E. Donaghey, D. I. James, C. B. Nielsen, B. C. Schroeder and W. Zhang, Acc. Chem. Res.; 2012, 45, 714.

[10]. Mark S. Chen, Jeremy R. Niskala, David A. Unruh, Crystal K. Chu, Olivia P. Lee and Jean M. J. Fréchet, Chem. Mater.; 2013, 25, 4088.

[11]. T. Lei, J. Dou and J. Pei, Adv. Mater.; 2012, 24, 6457.

[12]. W. Li, K. H. Hendriks, M. M. Wienk and R. J. Janssen, Acc. Chem. Res.;2016, 49, 78.

[13]. E. Wang, W. Mammo and M. R. Andersson, Adv. Mater.; 2014, 26, 1801.

[14]. J. Mei, K. R. Graham, R. Stalder and J. R. Reynolds, Org. Lett.; 2010, 12, 660.

[15] C. Kim, J. Liu, J. Lin, Arnold. B.Tamayo, B. Walker, G. Wu and T-Q. Nguyen. Chem. Mater.; 2012, $24,1699$.

[16]. I. Meager, M. Nikolka, B. C. Schroeder, C. B. Nielsen, M. Planells, H. Bronstein, J. W. Rumer, D. I. James, R. S. Ashraf, A. Sadhanala, P. Hayoz, J.-C. Flores, H. Sirringhaus and I. McCulloch, Adv. Funct. Mater.; 2014, 24, 7109.

[17].R. S. Ashraf , A. J. Kronemeijer, D. James, H. Sirringhaus and I. McCulloch , Chem. Commun.; 2012, 48, 3939.

[18]W. Yue, R. S. Ashraf, C. B. Nielsen, E. Collado-Fregoso, M. R. Niazi, S. A. Yousaf, M. Kirkus, H-Y Chen, A. Amassian, J. R. Durrant and I. McCulloch, Adv. Mater.; 2015, 27, 4702.

[19]. W. Yue, M. Nikolka, M. Xiao, A. Sadhanala, C. B. Nielsen, A. J. P. White, H-Y. Chen, A. Onwubiko, H. Sirringhaus and I. McCulloch. J. Mater. Chem. C.; 2016, 4, 9704.

[20]. J. Huang, Z. Mao, Z. Chen, D. Gao, C. Wei, W. Zhang andG. Yu, Chem. Mater.; 2016, 28, 2209.

[21]. J. Kirkpatrick, C. B. Nielsen,W. Zhang, H. Bronstein, R. S. Ashraf, M. Heeney, I. McCulloch, Adv. Energy. Mater.; 2012,2 , 260.

[22]. R. J. Janssen and J. Nelson, Adv. Mater.; 2013, 25, 1847. 